\title{
Progression of the Dose-Related Effects of Estrogenic Endocrine Disruptors, an Important Factor in Declining Fertility, Differs between the Hypothalamo- Pituitary Axis and Reproductive Organs of Male Mice
}

\author{
Katsuhiko WARITA ${ }^{1)}$, Teruo SUGAWARA ${ }^{2)}$, Zhan-Peng YUE ${ }^{3)}$, Shinji TSUKAHARA ${ }^{4)}$, Ken-ichiro MUTOH ${ }^{5}$, \\ Yoshihisa HASEGAWA ${ }^{6}$, Hiroshi KITAGAWA ${ }^{1)}$, Chisato MORI ${ }^{7)}$ and Nobuhiko HOSHI ${ }^{1) *}$ \\ ${ }^{1)}$ Department of Bioresource and Agrobiosciences, Graduate School of Science and Technology, Kobe University, Kobe 657-8501, \\ ${ }^{2)}$ Department of Molecular Biochemistry, Graduate School of Medicine, Hokkaido University, Sapporo 060-8638, ${ }^{3)}$ Department of \\ Histology and Embryology, Veterinary College, Jilin University, Changchun, Jilin, 130062, P. R. China, ${ }^{4}$ Division of Environmental \\ Health Sciences, National Institute for Environmental Studies, Tsukuba 305-8506, ${ }^{5)}$ Departments of Veterinary Anatomy and \\ ${ }^{6)}$ Experimental Animal Science, School of Veterinary Medicine and Animal Sciences, Kitasato University, Towada 034-8628 and \\ ${ }^{7)}$ Department of Bioenvironmental Medicine, Graduate School of Medicine, Chiba University, Chiba 260-8670, Japan
}

(Received 9 June 2006/Accepted 25 July 2006)

ABSTRACT. For the purpose of investigation of working mechanisms in endocrine disruptors, we evaluated the dose-related effects of fetal and/or neonatal exposure to an estrogenic compound on the male reproductive organs in adult mice, particularly with respect to gene expression of steroidogenic acute regulatory protein (StAR). The pregnant ICR mice were given subcutaneous injections of $10 \mu \mathrm{g} / \mathrm{day} /$ animal of diethylstilbestrol (DES) to subject the fetal mice to in utero exposure (IUE). Subsequently, the newborn male mice were subjected to neonatal exposure (NE) by treatment with vehicle or $0.1-10 \mu \mathrm{g} / \mathrm{day} /$ animal of DES. Fertility rates of each group were as follows: control, 100\%; IUE only, $60 \%$; IUE $+\mathrm{NE} 0.1 \mu \mathrm{g}, 25 \%$; IUE $+\mathrm{NE} 1 \mu \mathrm{g}, 0 \%$; IUE $+\mathrm{NE} 10 \mu \mathrm{g}, 0 \%$. In general histology, germ cell layers in the seminiferous tubules were thinned in the group of IUE+NE $10 \mu \mathrm{g}$. Hypoplasia of the Leydig cells, in which the staining intensity of eosin was diminished, was also observed in the groups of IUE+NE $0.1-10 \mu \mathrm{g}$. The androgen receptor (AR) and estrogen receptor alpha $(\mathrm{ER} \alpha)$ immunoexpression in the Leydig cells of IUE+NE 1-10 $\mu \mathrm{g}$ was slightly lower than that in the controls. Longterm dysfunction of the hypothalamo-pituitary-testicular axis, including sustained hypoproduction of gonadotropin and testosterone, and altered expressions of steroid hormone receptors and StAR genes were observed. The hypothalamo-pituitary control of gonadotropin secretion may be affected by the smaller doses of estrogenic agents than the reproductive organs. Furthermore, the fertility rate in the male mice exposed to this estrogenic agent was closely correlated with the testosterone levels, and even more so with the rate-limiting factor of steroidogenesis, StAR. This finding suggests that endocrine disruptors have an important pronounced effect on StAR gene expression.

KEY WORDS: diethylstilbestrol (DES), endocrine disruptors, fertility rate, fetal and/or neonatal exposure, steroidogenic acute regulatory protein (StAR).

J. Vet. Med. Sci. 68(12): 1257-1267, 2006

It is well known that many chemicals released into the environment potentially disrupt the endocrine system, and that some of them exhibit estrogenic activity by binding to estrogen receptors (ERs). Recent reports about the possible disruption of development and reproductive functions caused by a variety of environmental contaminants with estrogenic or anti-androgenic properties have heightened public concerns about the adverse health consequences of these chemicals for many species, including humans. These compounds include some polycyclic aromatic hydrocarbons, chlorinated organic compounds and pharmaceutical agents. Mice exposed prenatally to these compounds provide a model for exploration in humans, because the genital development of newborn mice corresponds approximately to that of the human fetus at the end of the first trimester. The fetal and neonatal period has a clinical window that is particularly sensitive to exposure to exogenous estrogenic compounds. Furthermore, long-term changes, including

\footnotetext{
* Correspondence to: Hoshi, N., Graduate School of Science and Technology, Kobe University, 1-1 Rokkodai-cho, Nada-ku, Kobe 657-8501, Japan.
}

molecular alterations, have been observed after exposure to endocrine disrupting chemicals during these early developmental periods $[13,28]$. In addition, it has been reported that neonatal exposure of animals to estrogenic compounds caused disorders of the male reproductive tract [24], reduction of testosterone [3], testicular atrophy and carcinoma $[17,21]$, increased rate of breast cancer [8], uterine adenocarcinoma and various cervicovaginal lesions [18, 20]. Diethylstilbestrol (DES), a synthetic non-steroidal estrogen, exhibits a high estrogenic activity by binding to the ERs, and is thus a useful model compound for evaluating the potential toxicity of a wide range of chemicals that affect or mimic estrogen activity [7]. Previous studies have shown that fetal and/or neonatal treatment of rodents with DES induces adverse changes similar to those that occur after administration of estradiol-17 $\beta[1,10,34]$, dichlorodiphenyl trichloroethane (DDT) and methoxychlor (an estrogenic pesticide currently used as a substitute for DDT) $[14,38]$. It is suggested that many of the adverse changes to the testis and reproductive tract induced by exposure to estrogens result from a combination of high estrogen and low andro- 
gen activity [39]. ER-knockout mice [9], in which the form of the $E R$ is inactivated, are infertile because of impaired fluid resorption from the efferent ducts [12]. On the other hand, a clinical study of patients with androgen insensitivity syndrome has shown that these patients are at high risk for testicular cancer [19]. These findings in the ER and androgen receptor (AR) may constitute indirect evidence of a role of estrogen or androgen activity inhibition in reproductive dysfunction.

For the purpose of investigation of working mechanisms in estrogenic endocrine disruptors, we administered DES to male mouse fetuses or neonates, then examined the doserelated effects on their hypothalamo-pituitary axis and reproductive organs in adulthood. By using four doses of DES, we were able to establish a range of reproductive dysfunction, with the fertility rates declining in inverse proportion to the dose. This allowed us to clarify the detailed mechanism of action of this estrogenic agent at doses with effects intermediate between fertility and infertility. The 8week-old mice were evaluated by means of morphological, endocrinological and molecular-toxicological analyses, particularly with respect to the gene expression of the steroidogenic acute regulatory protein $(S t A R)$, which mediates the rate-limiting and acutely regulated step in steroidogenesis.

\section{MATERIALS AND METHODS}

Animals: ICR mice were purchased from Japan SLC Inc. (Hamamatsu, Japan) and were bred in our own animal facility. All mice were kept under a $14 \mathrm{hr}$ light/10 hr dark condi- tion at $21-24^{\circ} \mathrm{C}$ with $45-55 \%$ relative humidity. They were allowed access to an MR-A1 laboratory diet (NOSAN Corp., Yokohama, Japan) and tap water ad libitum. All animals were handled with humane care under the guidelines for animal experiments at Kitasato University. Fifteen female ICR mice in proestrus were mated 1:1 with males overnight, and females that had a vaginal plug on the following morning were designated as being at gestational day (GD) 0 . The 12 dams were given subcutaneous injections of $10 \mu \mathrm{g} /$ day/animal of DES (Sigma-Aldrich Corp., St. Louis, U.S.A.) in $10 \mu l$ of sesame oil (KANTO CHEMICAL Co., Inc., Tokyo, Japan) on GD 7, 10, 13 and 16 to establish an in utero exposure (IUE) condition for fetal mice (Fig. 1). After the deliveries, the dams and their pups were allocated to 4 groups. The following daily administrations of vehicle or $0.1-10 \mu \mathrm{g} / \mathrm{day} /$ pup of DES were carried out subcutaneously from postnatal day (PND) 3 to PND 7 as a neonatal exposure (NE): for Group 1, sesame oil without DES (IUE only); for Group 2, $0.1 \mu \mathrm{g}$ of DES (IUE+NE $0.1 \mu \mathrm{g}$ ); for Group 3, $1 \mu \mathrm{g}$ of DES (IUE+NE $1 \mu \mathrm{g}$ ); and for Group 4, $10 \mu \mathrm{g}$ of DES (IUE+NE $10 \mu \mathrm{g}$ ). As a control group, 3 dams and their pups were treated with an equivalent volume of the vehicle. The body weights of each group were measured every week, and the male mice were sacrificed at 8 weeks of age. Blood samples were taken under ether anesthesia for measurement of plasma follicle-stimulating hormone (FSH), luteinizing hormone (LH), and testosterone levels. The testis, epididymis and seminal vesicles with coagulating glands were excised and weighed.

Fertility test: The 4-8 males from each group that had reached 8 weeks of age were mated with untreated females

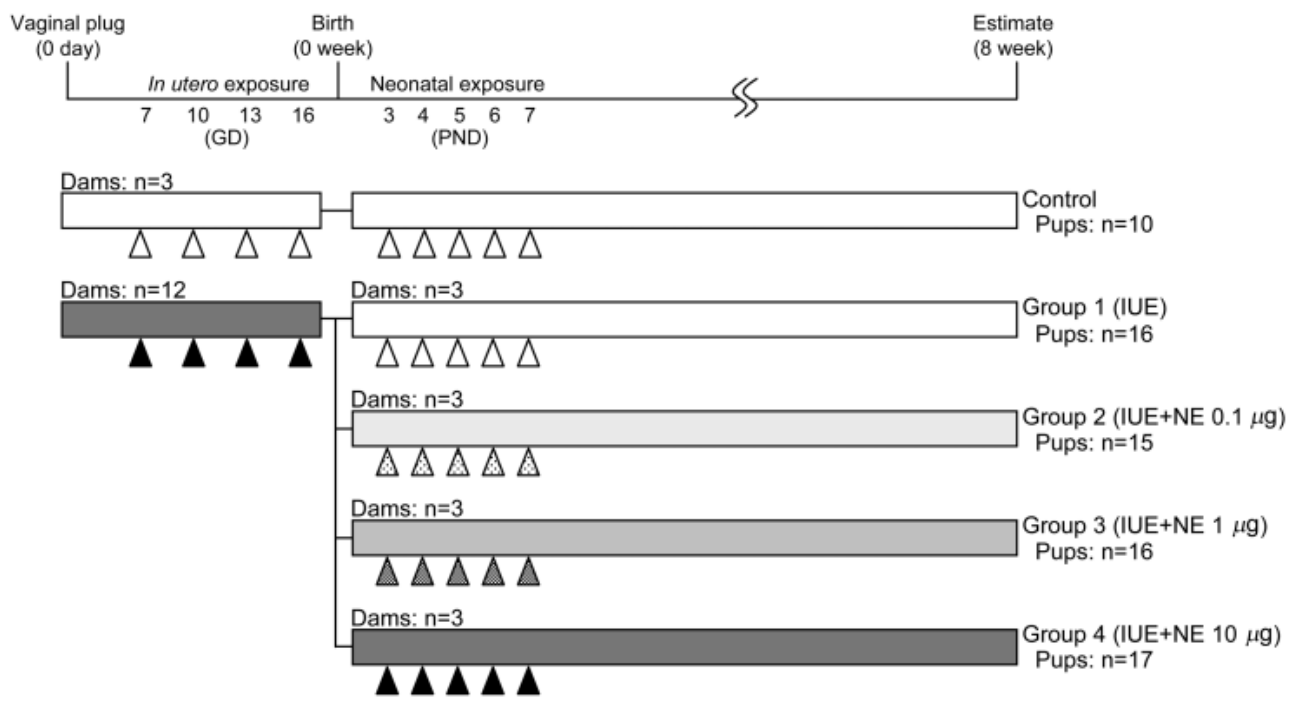

Fig. 1. Experimental protocol. The 12 dams were given subcutaneous injections of $10 \mu \mathrm{g} / \mathrm{day} / \mathrm{animal}$ of DES ( $\Delta$ ) on GD 7, 10, 13 and 16 to establish an in utero exposure (IUE) condition for fetal mice. After the deliveries, the dams and pups were allocated to 4 groups. The following daily administrations of vehicle or $0.1-10$ $\mu \mathrm{g} / \mathrm{day} /$ pup of DES were carried out subcutaneously from PND 3 to PND 7 as a neonatal exposure (NE): for Group 1, sesame oil $(\triangle)$ without DES (IUE only); for Group 2, $0.1 \mu \mathrm{g}(\Delta)$ of DES (IUE+NE $0.1 \mu \mathrm{g}$ ); for Group 3, $1 \mu \mathrm{g}(\mathbb{\Lambda})$ of DES (IUE+NE $1 \mu \mathrm{g}$ ); and for Group 4, $10 \mu \mathrm{g}(\boldsymbol{\Lambda})$ of DES (IUE+NE $10 \mu \mathrm{g}$ ). 
of proven fertility for 2 weeks to establish that the males were fertile. Reproductive behavior in the male mice was confirmed by the presence of a vaginal plug in the female mice.

Histological and immunohistochemical analysis: The testis and epididymis were fixed in $10 \%$ neutral buffered formalin for $24 \mathrm{hr}$, then embedded in paraffin by a routine method. Sections were cut at $5 \mu \mathrm{m}$ thickness for histological and immunohistochemical analysis. The specimens for the general histological analysis were stained with hematoxylin and eosin (H\&E). The immunohistochemical staining was carried out by the labeled streptavidin biotinylated antibody (LSAB) method using a Histofine SAB-PO (R) Kit (Nichirei Corp., Tokyo, Japan). Deparaffinized sections for the immunohistochemical analysis were treated with a temperature-controllable microwave processor (MI-77; Azumaya, Tokyo, Japan) in $10 \mathrm{mM}$ sodium citrate buffer (pH 6.0) for antigen retrieval, washed in $10 \mathrm{mM}$ phosphatebuffered saline (PBS), and then treated with $0.3 \% \mathrm{H}_{2} \mathrm{O}_{2}$ dissolved in $100 \%$ methanol to inactivate endogenous peroxidase activity. The primary antibodies for AR and ER $\alpha$ (Affinity BioReagents, Inc., Golden, U.S.A.) were diluted 1:200 in PBS and incubated over the sections in a humidified chamber for $14 \mathrm{hr}$ at $4^{\circ} \mathrm{C}$. Immunoreactions were visualized with 3,3'-diaminobenzidine. Negative controls, in which the primary antibodies were replaced with nonimmunized serum, did not show non-specific staining.

Plasma hormone measurement: Plasma hormones were measured by the time-resolved fluoroimmunoassay (TRFIA) method [31].

Plasma FSH and LH levels were measured according to a modified method described previously [31] using Europium (Eu)-labeled rat FSH or rat LH, and diluted anti-FSH or -LH rabbit serum, respectively.

The testosterone level was measured using Eu-labeled rabbit antibody against bovine serum albumin (BSA) conjugated with testosterone, and polystyrene microtiter strips (Nunc-Immuno ${ }^{\mathrm{TM}}$ Modules; Nalge Nunc, Tokyo, Japan) coated with BSA-testosterone conjugate. Seventy $\mu l$ of the plasma was diluted in $430 \mu l$ of physiological saline, and 3 $\mathrm{m} l$ of diethyl ether was added to extract testosterone from the plasma. The organic phase was transferred to another tube, and was volatilized by a dry thermo unit. The evaporated organic phase was reconstituted with $350 \mu l$ of the assay buffer (140 mM NaCl, 0.5\% BSA, 0.05\% $\gamma$-globulin, $0.00078 \%$ DTPA, $0.05 \%$ sodium azide, $0.01 \%$ Tween 40 and $50 \mathrm{mM}$ Tris-HCl, $\mathrm{pH} 7.8$ ). After washing all wells of microtiter strips, $100 \mu \mathrm{l} / \mathrm{well}$ of serial diluted standard $(0.001-10 \mathrm{ng} / \mathrm{ml})$ and reconstituted samples were distributed. Then, the Eu-labeled antibody for BSA-testosterone conjugate was added to each well and incubated for $4 \mathrm{hr}$. After washing all wells, enhancement solution (100 $\mu \mathrm{l} /$ well) was added and the fluorescence intensity of each well was measured with the time-resolved fluorometer (Multilabel Counter, 1420 ALVO, Wallac Oy, Finland).

$R N A$ extraction and RT-PCR: To examine molecular-toxicological changes in the testis and epididymis, mRNA expressions of $A R, E R \alpha$ and $S t A R$ were examined by semiquantitative RT-PCR methods. Total cellular RNAs were extracted from the frozen testis or epididymis by homogenization with TRIzol Reagent ${ }^{\mathrm{TM}}$ (Invitrogen Corporation, Carlsbad, U.S.A.). The mRNA was reverse-transcribed to cDNA using a Super Script ${ }^{\mathrm{TM}}$ First-Strand Synthesis System (Invitrogen Corporation). The cDNA was amplified by PCR with Taq DNA polymerase (TaKaRa Bio, Otsu, Japan) and each of the specific primers for $A R, E R \alpha, S t A R$ and glyceraldehyde-3-phosphate dehydrogenase (GAPDH). The sequences of the oligonucleotides were as follows: for $A R$, sense primer 5'-CAG CAC ACT GAG GAT GGT TC3 ' and anti-sense primer 5'-TCA TCC TGA TCT GGA GGA GC-3'; for $E R \alpha$, sense primer 5'-GCC TCT GGC TAC CAT TAT GG-3' and anti-sense primer 5'-CAT CTC TCT GAC GCT TGT GC-3'; for StAR, sense primer 5'GTT CCT CGC TAC GTT CAA GC-3' and anti-sense primer 5'-GAA ACA CCT TGC CCA CAT CT-3'; for $G A P D H$, sense primer 5'-ACC ACA GTC CAT GCC ATC AC-3' and anti-sense primer 5'-TCC ACC ACC CTG TTG CTG TA-3'. The following conditions were used for the amplification: $30 \mathrm{sec}$ of denaturing at $95^{\circ} \mathrm{C}, 30 \mathrm{sec}$ of annealing at $58^{\circ} \mathrm{C}$, and $1 \mathrm{~min}$ of extending at $72^{\circ} \mathrm{C}$. PCR was carried out in 28 cycles for the $A R$ and $E R \alpha$ and 19 cycles for the StAR and GAPDH. The PCR products were subjected to electrophoresis in a $2.5 \%$ agarose gel containing ethidium bromide. The intensity of the ethidium bromide luminescence was measured using NIH Image software. Data were normalized for GAPDH mRNA levels in each sample and expressed as a value relative to the control.

Statistical analysis: Statistical analyses were performed with StatView software for Windows (version 5.0; SAS Institute Inc., Cary, U.S.A.). The data of body weight, organ weight, hormone level and gene expression were analyzed by one-way analysis of variance (ANOVA) and TukeyKramer multiple comparison test. Fisher's exact probability test was applied to the analysis of fertility rate. Results were considered significant when the $P$ value was less than 0.05 .

\section{RESULTS}

Body weights: Body weights throughout the experimental period are summarized in Table 1 . In general, the body weights of the control and DES-exposed groups increased gradually and progressively with age. Group 4 showed a significant reduction in the body weight from the age of 1 week to the end of the experimental period ( 8 weeks) compared with all other groups $(P<0.05$, respectively). The body weights of Group 3 were significantly lower than those of Group 1 from 2 to 5 weeks of age $(P<0.05$, respectively). Group 2 showed a significant reduction in the body weight at 2 weeks of age relative to Group $1(P<0.05)$. The body weight of Group 1 was significantly higher than that of the control at 2 weeks of age.

Fertility: The fertility rates of each group are summarized in Table 2. Three of five males in Group 1 and one of four 
Table 1. Effects of fetal and/or neonatal treatment of DES on the body weights throughout the experimental period (mean $\pm \mathrm{SD})$

\begin{tabular}{cccccc}
\hline \multirow{2}{*}{$\begin{array}{c}\text { Age } \\
\text { (week) }\end{array}$} & Control $(\mathrm{n}=10)$ & Group 1 $(\mathrm{n}=16)$ & Group 2 $(\mathrm{n}=15)$ & Group 3 $(\mathrm{n}=16)$ & Group 4 $(\mathrm{n}=17)$ \\
\cline { 2 - 5 } & $6.28 \pm 0.51$ & $6.59 \pm 0.27$ & $6.47 \pm 0.49$ & $6.30 \pm 0.64$ & $5.90 \pm 0.59^{*, \mathrm{a}, \mathrm{b}, \mathrm{c}}$ \\
2 & $10.34 \pm 0.67$ & $11.30 \pm 0.60^{*}$ & $10.44 \pm 0.83^{\mathrm{a}}$ & $9.75 \pm 1.15^{\mathrm{a}}$ & $7.51 \pm 0.84^{*, \mathrm{a}, \mathrm{b}, \mathrm{c}}$ \\
3 & $18.01 \pm 1.55$ & $18.50 \pm 0.54$ & $18.60 \pm 1.50$ & $17.04 \pm 1.52^{\mathrm{a}}$ & $14.66 \pm 1.44^{*, \mathrm{a}, \mathrm{b}, \mathrm{c}}$ \\
4 & $30.58 \pm 1.46$ & $31.76 \pm 1.08$ & $30.12 \pm 1.46$ & $28.85 \pm 1.94^{\mathrm{a}}$ & $25.59 \pm 2.16^{*, \mathrm{a}, \mathrm{b}, \mathrm{c}}$ \\
5 & $36.01 \pm 2.37$ & $37.45 \pm 1.85$ & $35.98 \pm 2.03$ & $35.28 \pm 2.20^{\mathrm{a}}$ & $31.62 \pm 1.88^{*, \mathrm{a}, \mathrm{b}, \mathrm{c}}$ \\
6 & $38.60 \pm 2.21$ & $40.01 \pm 2.10$ & $39.56 \pm 2.58$ & $40.01 \pm 2.10$ & $34.89 \pm 3.29^{*, \mathrm{a}, \mathrm{b}, \mathrm{c}}$ \\
7 & $39.87 \pm 1.98$ & $42.42 \pm 2.58$ & $40.78 \pm 2.54$ & $41.29 \pm 2.95$ & $36.78 \pm 3.48^{*, \mathrm{a}, \mathrm{b}, \mathrm{c}}$ \\
8 & $41.64 \pm 2.09$ & $44.36 \pm 2.70$ & $42.06 \pm 2.37$ & $41.80 \pm 3.33$ & $37.76 \pm 3.53^{*, \mathrm{a}, \mathrm{b}, \mathrm{c}}$ \\
\hline
\end{tabular}

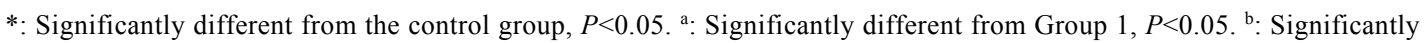
different from Group 2, $P<0.05$. ${ }^{\text {: }}$ Significantly different from Group 3, $P<0.05$. The data were analyzed using Tukey-Kramer multiple comparison test.

Table 2. Effects of fetal and/or neonatal treatment with DES on the fertility rate of each group, and the absolute and relative organ weights of the testis, epididymis and seminal vesicles at 8 weeks of age

\begin{tabular}{|c|c|c|c|c|c|}
\hline & Control & Group 1 & Group 2 & Group 3 & Group 4 \\
\hline \multicolumn{6}{|l|}{ Fertility rate } \\
\hline Delivered/no. tested & $7 / 7$ & $3 / 5$ & $1 / 4^{\#}$ & $0 / 8^{\# \# \#}$ & $0 / 8^{\# \# \#}$ \\
\hline \multicolumn{6}{|c|}{ Absolute organ weights (mg) } \\
\hline Testis & $137.5 \pm 13.8$ & $140.0 \pm 18.6$ & $93.0 \pm 6.2^{*, \mathrm{a}}$ & $96.6 \pm 10.4^{*, \mathrm{a}}$ & $91.5 \pm 5.6^{*, \mathrm{a}}$ \\
\hline Epididymis & $47.8 \pm 2.9$ & $49.4 \pm 3.9$ & $38.0 \pm 3.2^{*, \mathrm{a}}$ & $34.3 \pm 1.5^{*, \mathrm{a}}$ & $35.9 \pm 4.0^{*, \mathrm{a}}$ \\
\hline Seminal vesicle & $329.5 \pm 10.8$ & $300.1 \pm 43.9$ & $288.9 \pm 50.8$ & $257.2 \pm 121.1$ & $249.7 \pm 90.3$ \\
\hline \multicolumn{6}{|c|}{ Relative organ weights (\%) } \\
\hline Testis & $0.343 \pm 0.040$ & $0.312 \pm 0.046$ & $0.220 \pm 0.018^{*, \mathrm{a}}$ & $0.231 \pm 0.014^{*, \mathrm{a}}$ & $0.238 \pm 0.023^{*, \mathrm{a}}$ \\
\hline Epididymis & $0.119 \pm 0.008$ & $0.110 \pm 0.008$ & $0.090 \pm 0.005^{*, \mathrm{a}}$ & $0.083 \pm 0.010^{*, \mathrm{a}}$ & $0.094 \pm 0.013^{*, \mathrm{a}}$ \\
\hline Seminal vesicle & $0.823 \pm 0.038$ & $0.668 \pm 0.106$ & $0.684 \pm 0.139$ & $0.602 \pm 0.273$ & $0.655 \pm 0.248$ \\
\hline
\end{tabular}

males in Group 2 mated successfully, with the matings resulting in the birth of a litter; however, all of the males in Groups 3 and 4 either were infertile or did not mate. There was a significant difference between the fertility rate in the control group and those in each of Group $2(P<0.05)$, Group $3(P<0.001)$ and Group $4(P<0.001)$. Although infertile males were observed in Group 1, $P$ value did not achieve statistical significance compared with the controls $(P=0.15)$. All the DES-exposed males were fertile, as confirmed by the formation of a vaginal plug in female mice.

Necropsy findings and organ weights: Slightly smaller testes and accessory reproductive organs were observed in Groups 2, 3 and 4 compared with the controls at necropsy. There were no reproductive tract malformations in the DESexposed groups.

Absolute and relative (body weight ratio) weights of the bilateral testes, epididymides and seminal vesicles with coagulating glands are presented in Table 2. Statistically significant decreases in both the absolute and relative weights of the testis and epididymis were noted in Groups 2 , 3 and 4 relative to the controls and also relative to Group 1 $(P<0.01$ for all). In regard to the weight of the seminal ves- icles with the coagulating glands, no significant difference was detected between the controls and the DES-exposed groups.

Histological and immunohistochemical findings: Following DES administration, germ cell layers in the seminiferous tubules were thinned in Group 4. Hypoplasia of the Leydig cells, in which the staining intensity of eosin was diminished, was also observed in Groups 2 and 3, and even more markedly in Group 4 (Fig. 2). In Groups 3 and 4, there was hypoplasia of the epididymal ducts of the cauda epididymis (Fig. 3). The testis and epididymis of Group 1 had a normal appearance in the general histological analyses.

AR was positive in the nuclei of the Leydig cells and peritubular myoid cells in the testis, and in the nuclei of columnar epithelial cells in the epididymal duct (Fig. 4). The AR immunoexpression in the Leydig cells of Groups 3 and 4 was slightly lower than that in the controls. The AR immunoexpression in the epididymal ducts of Groups 2, 3 and 4 was diminished in inverse proportion to the dose of DES, and the decreases in Group 4 were especially pronounced.

The immunoreactivity for ER $\alpha$ was localized in the nuclei of the Leydig cells and spermatocytes in the testis, 

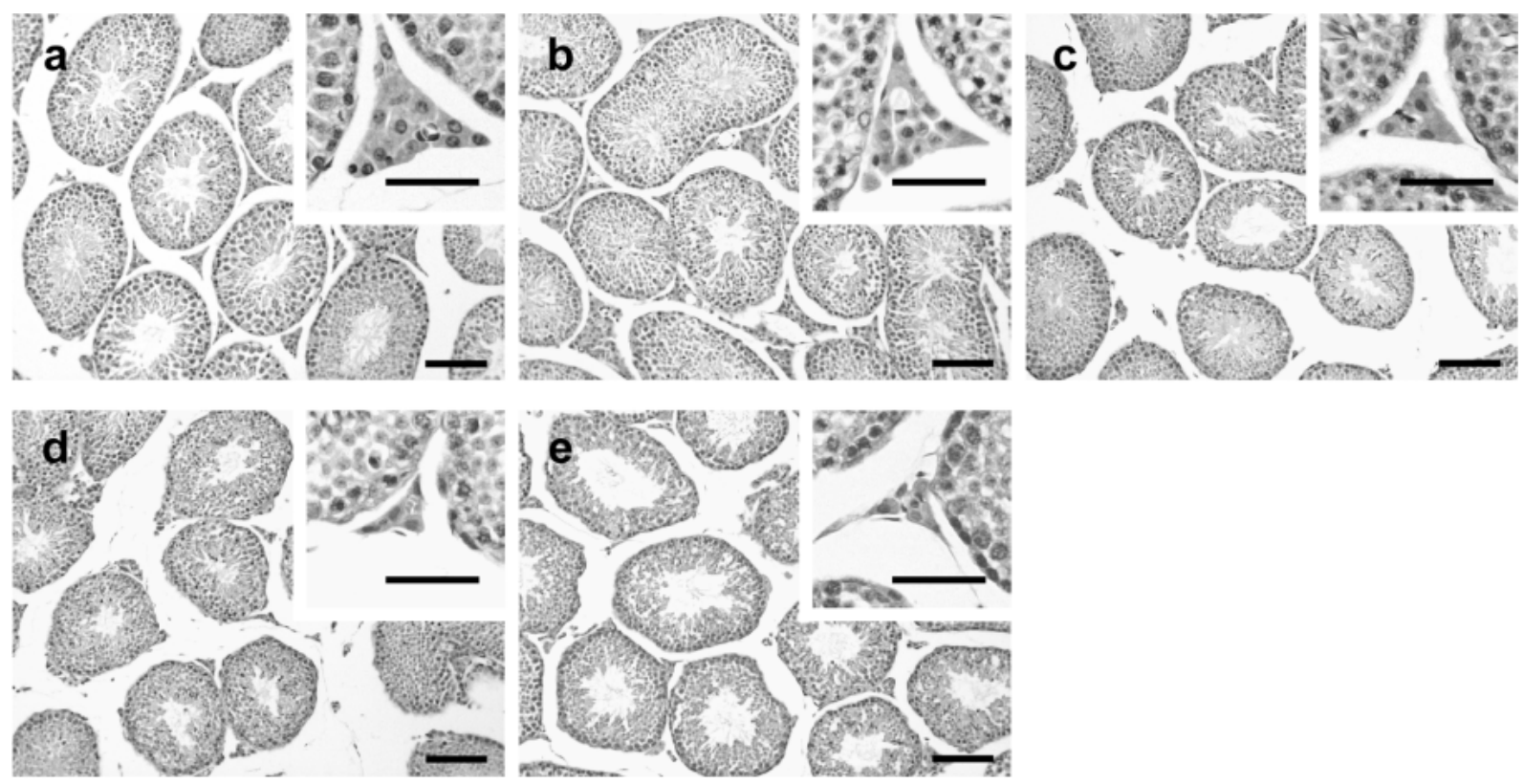

Fig. 2. Representative histology of the testis in the adult mice of control (a), Group 1 (b), Group 2 (c), Group 3 (d) and Group 4 (e). The germ cell layers in the seminiferous tubules of Group 4 were thinned compared with those of the control. Small Leydig cells and low staining intensity of eosin were observed in Groups 2 and 3, and even more markedly in Group 4 (Bars=100 $\mu$ m). The inset shows higher magnification of the Leydig cells (Bars $=50 \mu \mathrm{m})$. H\&E staining.
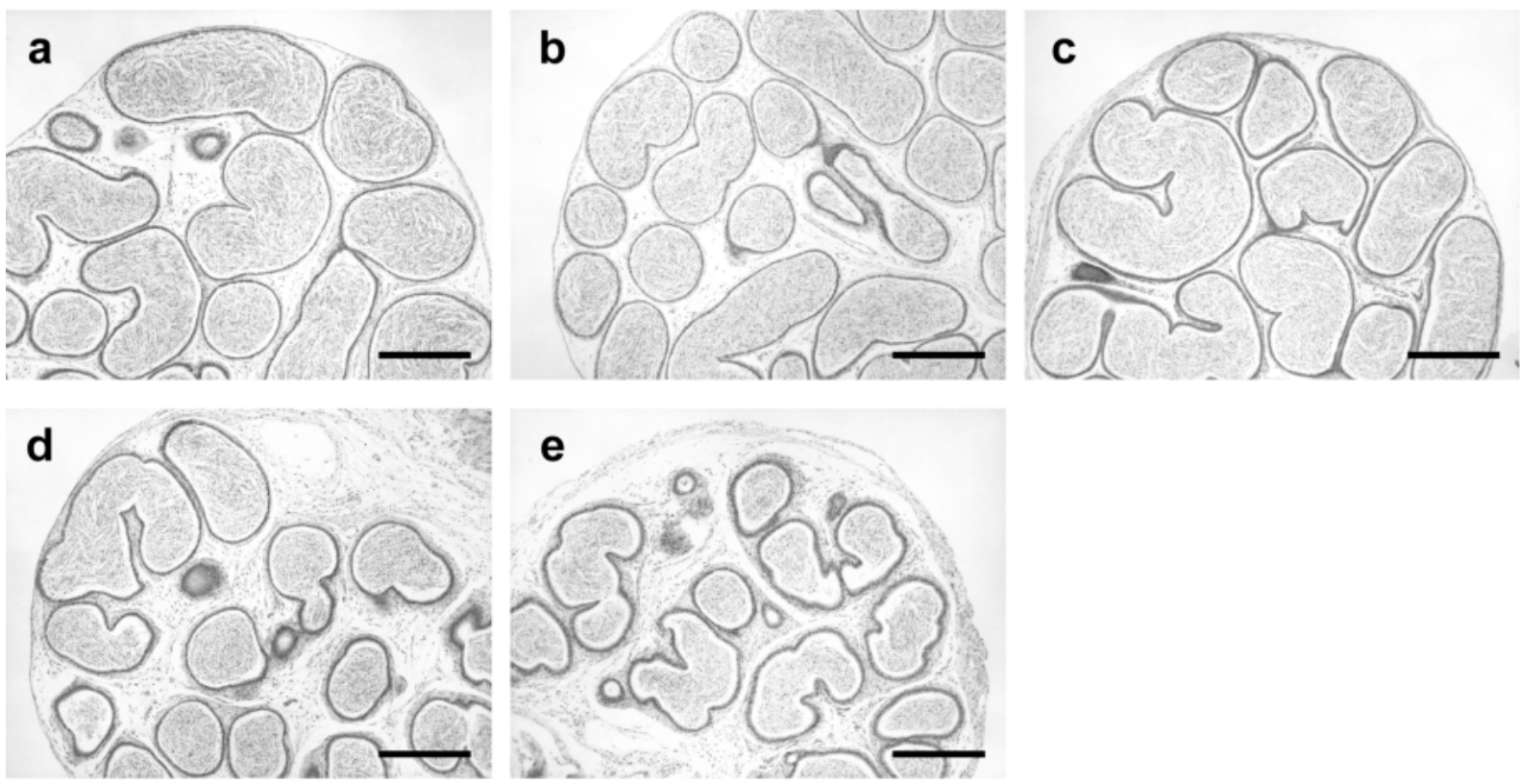

Fig. 3. Representative histology of the cauda epididymis in adult mice of control (a), Group 1 (b), Group 2 (c), Group 3 (d) and Group 4 (e). The decrease in diameter of the epididymal ducts and the increase in connective tissue were observed in Groups 3 and 4 (Bars $=400$ $\mu \mathrm{m})$. H\&E staining.

and in the columnar epithelial cells in the epididymal duct, especially in the efferent ductules (Fig. 5). The ER $\alpha$ immunoexpression of the Leydig cells was diminished in Group 3, and even more markedly in Group 4; however, no difference was detected in the columnar epithelial cells of the efferent ductules between the control and DES-exposed groups.

Plasma hormone measurement (Fig. 6): The FSH levels in the DES-exposed groups decreased in inverse proportion to the dose, and a significant reduction was seen in Group 3 $(P<0.05)$ and Group $4(P<0.01)$ compared with the controls. 


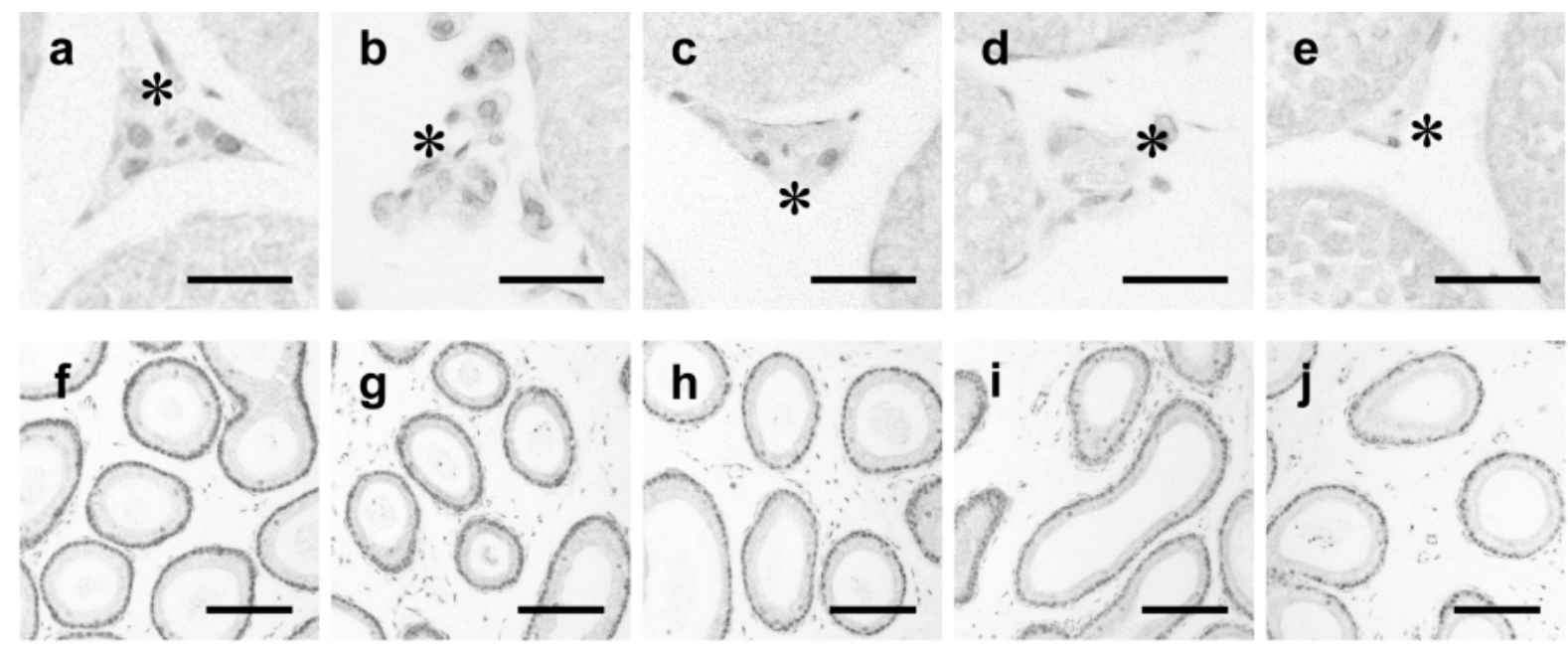

Fig. 4. AR was positive in the nuclei of the Leydig cells and peritubular myoid cells in the testis of control (a), Group 1 (b), Group 2 (c), Group 3 (d) and Group 4 (e). The AR immunoexpression in the Leydig cells (*) of Groups 3 and 4 was slightly lower than that in the controls $($ Bars $=50 \mu \mathrm{m})$. In the epididymis, the AR was positive in the nuclei of columnar epithelial cells in the epididymal duct of control (f), Group 1 (g), Group 2 (h), Group 3 (i) and Group 4 (j). The AR immunoexpression in the epididymal ducts of Groups 2, 3 and 4 was diminished in inverse proportion to the dose of DES, and the decreases in Group 4 were especially pronounced $($ Bars $=100 \mu \mathrm{m})$.
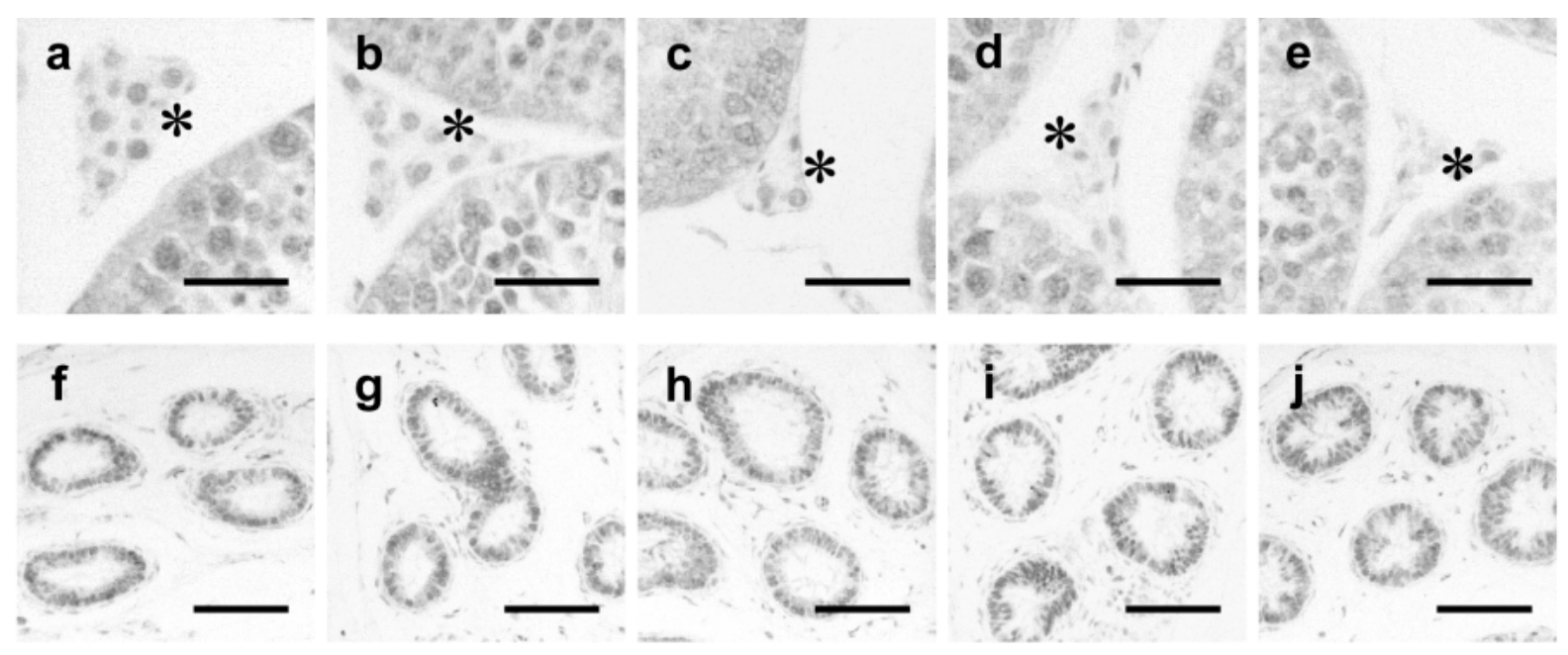

Fig. 5. The immunoreactivity for ER $\alpha$ was localized in the nuclei of the Leydig cells and spermatocytes in the testis of control (a), Group 1 (b), Group 2 (c), Group 3 (d) and Group 4 (e). The ER $\alpha$ immunoexpression of the Leydig cells (*) was diminished in Group 3 , and even more markedly in Group $4($ Bars $=50 \mu \mathrm{m})$. In the epididymis, the ER $\alpha$ was positive in the columnar epithelial cells in the epididymal duct, especially in the efferent ductules of control (f), Group 1 (g), Group 2 (h), Group 3 (i) and Group 4 (j). No difference was detected in the columnar epithelial cells of the efferent ductules between the control and DES-exposed groups.

In addition, a significant difference in LH levels was found in Group $2(P<0.01)$, Group $3(P<0.05)$ and Group 4 $(P<0.01)$. The testosterone levels in Groups 2, 3 and 4 were all significantly lower than those in the controls and Group 1 , respectively $(P<0.01$, for all).

RT-PCR (Fig. 7): The AR expression in the testis was not significantly different among groups. The expression of $E R \alpha$ in the testis of the DES-exposed groups decreased compared with the control group, and a significant difference was noted in Groups 3 and $4(P<0.05)$. Although Groups 1 and 2 showed no significant differences in the expression of $E R \alpha$ relative to the controls, a tendency of decrease was shown $(P=0.10, P=0.06$, respectively $)$. The StAR expressions in the testis of Groups 3 and 4 were significantly lower than those of the controls and Group 1, respectively $(P<0.01$ for all). The StAR expression in Group 2 tended to decrease compared with that of the controls $(P=0.14)$.

In regard to the epididymis, there was no significant change in the $A R$ and $E R \alpha$ expression in any of the groups; however, the $E R \alpha$ expression showed a tendency to decrease in the DES-exposed groups $(P=0.06)$. 

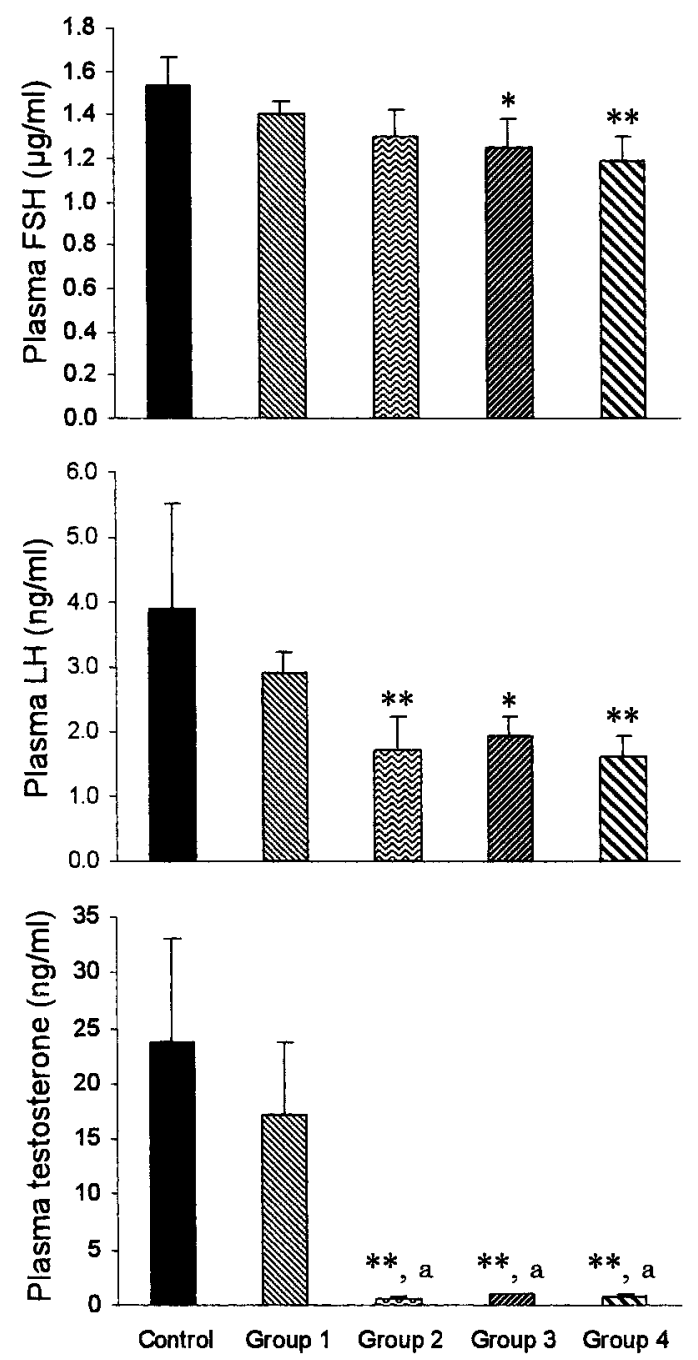

Fig. 6. Effect of fetal and/or neonatal treatment with DES on plasma levels of FSH, LH and testosterone. Each column is the mean+SD for 3-4 mice/group at 8 weeks of age. *: $P<0.05, * *: P<0.01$ (compared with respective value for the control). a: $P<0.01$ (significantly different from Group 1). The data were analyzed using TukeyKramer multiple comparison test.

\section{DISCUSSION}

Endocrine disruptors have been demonstrated to alter the endocrine system by mimicking the action of the sex hormones, interfering with membrane receptor binding, and inhibiting intracellular signaling. The hypothesis that exogenous estrogenic compounds act as disruptors of male reproductive tract development is well known. Previous reports have shown that fetuses are extremely sensitive to chemicals with hormone-like activity $[16,24,26]$, and that neonatal administration of estrogenic agents induces reductions in testis weight, sperm count and motility in adult male rodents $[11,35]$.
The purpose of this paper was to elucidate the detail mechanisms of the estrogenic endocrine disruptors. For that purpose, we clarified the dose-related effects of fetal and/or neonatal exposure to estrogenic agents on the fertility rate in the treated animals, particularly with respect to the gene expression of StAR. The treatment-induced changes in this study ranged from significant reproductive disorder in male mice by the highest dose of DES (IUE+NE $10 \mu \mathrm{g}$ ) to a slight effect on reproductive function by the lowest dose of DES (IUE only). Our results indicate that DES had detrimental dose-related effects on the histology, hormonal secretions and $A R, E R \alpha$ and $S t A R$ gene expressions of the testis and reproductive tract of adult male mice.

Previous studies have demonstrated that high doses of potent estrogens, such as DES, are clearly inhibitory to testicular development over both the short and long term [3, 25]. The results of the present histological analyses in the groups exposed to DES neonatally showed a thinning of germ cell layers in the seminiferous tubules, which suggests a reduction of spermatogenesis, and the hypoplasia of the Leydig cells and epididymal ducts of the cauda epididymis at 8 weeks of age; however, the groups exposed to DES in utero but not treated neonatally showed no histological changes in the testis or epididymis. This result suggests that the fetal exposure in mice did not lead to an impaired response of these organs.

The serum FSH level regulates spermatogenesis [40] and has been shown to change in parallel with the spermatogenic changes [2]. LH is known to bind with its own receptors in Leydig cells, and stimulates the transcription of genes encoding steroidogenic enzymes. We showed that the plasma FSH and LH levels in the DES-exposed groups were lower than those of the controls and decreased in inverse proportion to the dose. Furthermore, testosterone levels, which are directly involved in spermatogenesis [4, 27], were markedly reduced in the groups treated with DES neonatally. Primary points of control in steroidogenesis are the transport of cholesterol from intracellular stores to the inner mitochondrial membrane, and the subsequent conversion of cholesterol to pregnenolone by the cholesterol side-chain cleavage enzyme (P450scc) [6], which initiates the synthesis of all steroid hormones. The StAR protein mediates the rate-limiting and acutely regulated step in steroidogenesis $[15,29,30]$. LH stimulation is mediated by the $\mathrm{LH}$ receptor at the first step of the signaling pathway, and subsequently intercellular cAMP increases to stimulate the transcription of the StAR in mouse MA-10 cells [36]. In the present study, the LH and testosterone levels decreased significantly in the groups receiving IUE+NE $0.1-10 \mu \mathrm{g}$, whereas there was a significant reduction of $S t A R$ in the testis in the groups receiving IUE+NE $1-10 \mu \mathrm{g}$, in which all the animals were infertile. This result indicates that infertility in the DESexposed male mice was closely correlated with the significant decrease in the StAR expression in the testis. The ratelimiting factor of steroidogenesis in the testis holds extremely important clues to the presence or absence of fertility. Our results suggest that endocrine disruptors have 

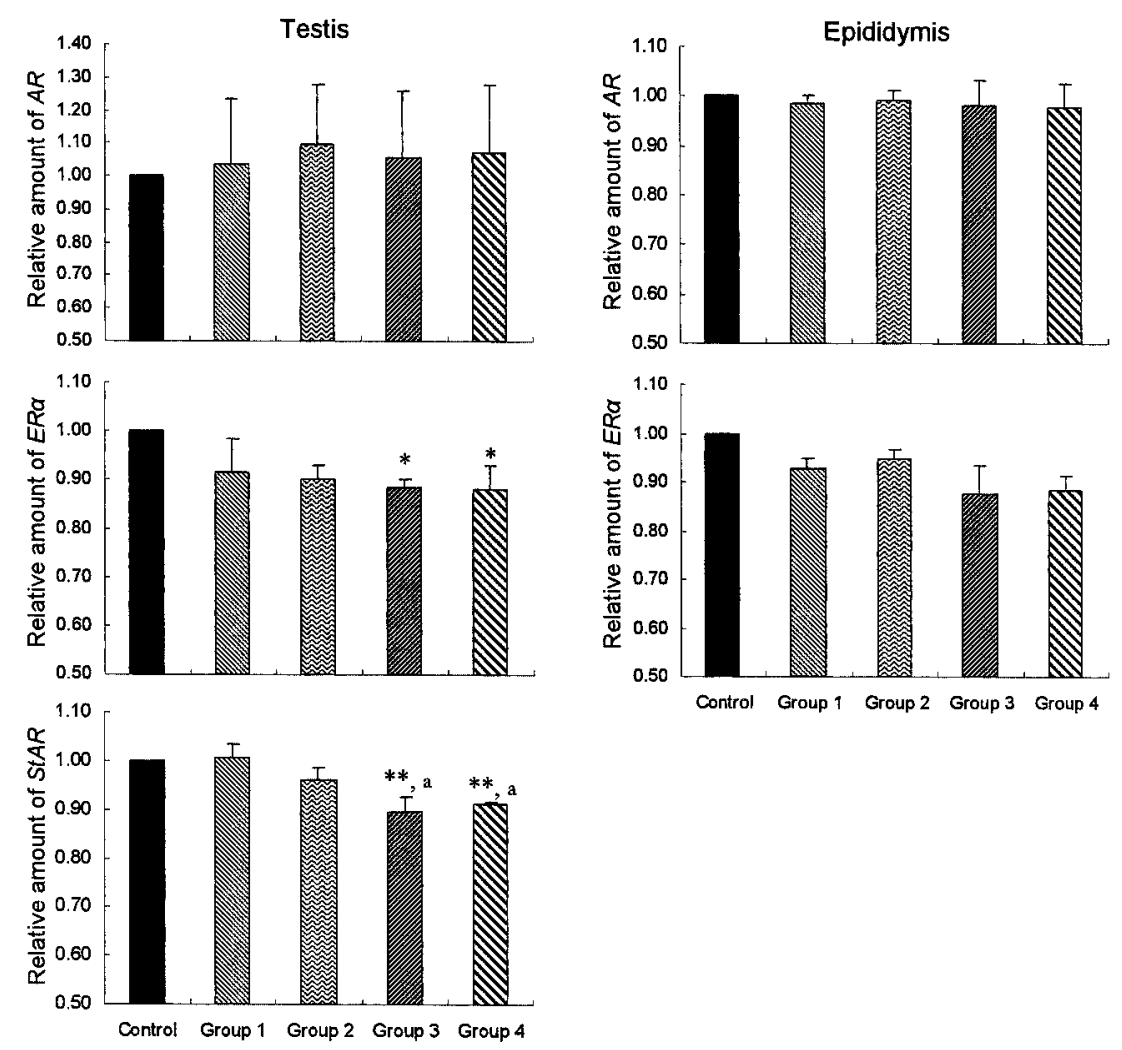

Fig. 7. Effect of fetal and/or neonatal treatment with DES on $A R, E R \alpha$ and StAR mRNA expression in the testis and epididymis. Each column is the mean+SD for 3-4 mice/group at 8 weeks of age. *: $P<0.05,{ }^{* *}: P<0.01$ (compared with respective value for the control). ${ }^{\text {a }}: P<0.01$ (significantly different from Group 1 ). The data were analyzed using Tukey-Kramer multiple comparison test.

important pronounced effects on the $S t A R$ gene expression.

AR immunoexpression is observed in nuclei of Leydig cells, Sertoli cells and peritubular myoid cells, while ER $\alpha$ immunoexpression is found in the nuclei of Leydig cell, spermatocytes and spermatids in testis [22, 37]. The AR immunoexpression in the testis was slightly reduced in the groups receiving IUE+NE 1-10 $\mu \mathrm{g}$ compared with the controls; however, there was no significant difference in the $A R$ mRNA expression. In contrast, the ER $\alpha$ immunoexpression in those groups tended to diminish in the testis, concomitant with a decrease in the ER $\alpha$ mRNA expression. The diminished immunoexpressions of $\mathrm{AR}$ and $\mathrm{ER} \alpha$ were considered to be due to reductions in the amount or activity of these factors, and may have been responsible for the observed reproductive dysfunction. In a previous study, in which a daily subcutaneous administration of DES $(0.5,5$ and $50 \mu \mathrm{g})$ was carried out neonatally for 5 days from the day of birth, there was a decrease of both $A R$ and $E R \alpha$ mRNA at 12 weeks of age (especially in the animals receiving 5 and $50 \mu \mathrm{g}$ treatment) [28]. In the present study, the plasma LH and testosterone levels in the group receiving IUE+NE $0.1 \mu \mathrm{g}$ were significantly lower than those of the control group, whereas there were no remarkable changes of the AR and ER $\alpha$ immunoexpression or in the expression of the $A R, E R \alpha$ and $S t A R$ genes. Thus, the dose of estrogenic agents necessary to induce hypothalamo-pituitary functional alteration may be lower than that required for testicular dysfunction.

The epididymis goes through a phase of relatively slow growth after birth, followed by rapid growth during and after puberty because of the onset of differentiation of Leydig cells and increasing testosterone levels [23, 32, 33]. The neonatal estradiol treatment acts indirectly on testicular development through an inhibition of gonadotropin secretion, and directly on the development of the sex accessory glands [5]. Although it is obviously difficult in the present study to disentangle possible direct effects of DES on the epididymis due to altered testosterone levels, the AR immunoreaction and $E R \alpha$ mRNA expression were slightly changed. There was no significant difference among groups in the $A R$ mRNA expression in the epididymis; however, the AR immunoexpressions were diminished in the groups exposed to DES neonatally. This data, including the results of the testosterone levels, indicates that the hypoplasia found in the general histological analyses of the epididymis was caused by reductions in both the testosterone level and AR activity. There was no detectable difference in the ER $\alpha$ 
Table 3. Outline of this study

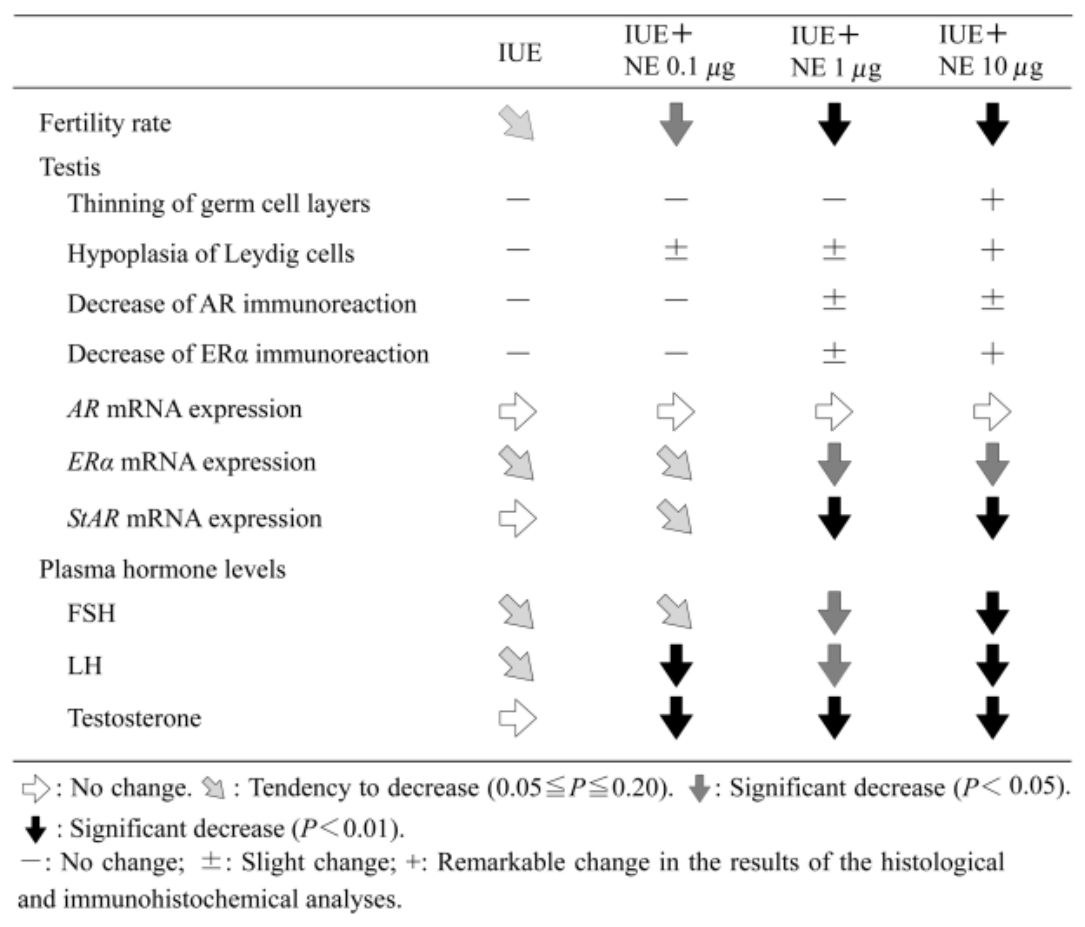

immunoexpressions in the epididymis between the control and DES-exposed groups, whereas the expression of ER $\alpha$ mRNA tended to decline in inverse proportion to the dose $(P=0.06)$. Further investigations will be needed to determine the biological significance of these results.

The results of this study are summarized in Table 3. The IUE group that was exposed to DES before the clinical window did not show considerably different histological findings compared with the control group; however, a minority of this group was infertile, and this minority tended to show lower gonadotropin secretion and ER $\alpha$ mRNA expression than the controls. The reduction of fertility rate in this group was likely caused by the decrease in these parameters, or perhaps DES altered the part of the brain most responsible for reproductive behavior. In our unpublished data, histological changes in mouse testis that were induced by neonatal administration of DES (100 $\mu \mathrm{g} / \mathrm{animal})$ at PND 3 were recovered transiently at 8 weeks of age by treatment with both activin and PMSG from 6 to 8 weeks of age; however, this was a short-lived effect. This result implies that estrogenic agents target the neuroendocrine system more effectively than the lower reproductive organs, because the testis maintains their ability to recover from dysfunction induced by DES.

In conclusion, in utero and/or neonatal exposure to DES in the male mice results in sustained hypoproduction of $\mathrm{FSH}, \mathrm{LH}$ and testosterone and alteration of gene expressions in steroid hormone receptors and StAR gene, and leads to long-term dysfunction of the hypothalamo-pituitary-testicular axis. The hypothalamo-pituitary control of gonadotropin secretion may be affected by the smaller doses of estrogenic agents than the reproductive organs. These findings suggest that dose-related progressive effect differs between hypothalamo-pituitary and reproductive organs of male mice, and estrogenic endocrine disruptors have an important pronounced effect on StAR gene expression.

ACKNOWLEDGMENTS. This work was supported by Grants-in-Aid for Scientific Research (C) (\#12836014), (B) (\#15390510) and for Scientific Research on Priority Areas (1) (\#14042260) from the Ministry of Education, Culture, Sports, Science and Technology of Japan (to N. Hoshi).

\section{REFERENCES}

1. Arai, Y., Mori, T., Suzuki, Y. and Bern, H. A. 1983. Long-term effects of perinatal exposure to sex steroids and diethylstilbestrol on the reproductive system of male mammals. Int. Rev. Cytol. 84: 235-268.

2. Atanassova, N., McKinnell, C., Turner, K. J., Walker, M., Fisher, J. S., Morley, M., Millar, M. R., Groome, N. P. and Sharpe, R. M. 2000. Comparative effects of neonatal exposure of male rats to potent and weak (environmental) estrogens on spermatogenesis at puberty and the relationship to adult testis size and fertility: Evidence for stimulatory effects of low estrogen levels. Endocrinology 141: 3898-3907.

3. Atanassova, N., Mckinnell, C., Walker, M., Turner, K. J., Fisher, J. S., Morley, M., Millar, M. R., Groome, N. P. and Sharpe, R. M. 1999. Permanent effects of neonatal estrogen exposure in rats on reproductive hormone levels, Sertoli cell number, and the efficiency of spermatogenesis in adulthood. Endocrinology 140: 5364-5373. 
4. Awoniyi, C. A., Zirkin, B. R., Chandrashekar, V. and Schlaff, W. D. 1992. Exogenously administered testosterone maintains spermatogenesis quantitatively in adult rats actively immunized against gonadotropin-releasing hormone. Endocrinology 130: 3283-3288.

5. Bellido, C., Pinilla, L., Aguilar, R., Gaytan, F. and Aguilar, E. 1990. Possible role of changes in post-natal gonadotrophin concentrations on permanent impairment of the reproductive system in neonatally oestrogenized male rats. J. Reprod. Fertil. 90: 369-374.

6. Clark, B. J., Wells, J., King, S. R. and Stocco, D. M. 1994. The purification, cloning, and expression of a novel luteinizing hormone-induced mitochondrial protein in MA-10 mouse Leydig tumor cells. Characterization of the steroidogenic acute regulatory protein (StAR). J. Biol. Chem. 269: 28314-28322.

7. Colborn, T., vom Saal, F. S. and Soto, A. M. 1993. Developmental effects of endocrine-disrupting chemicals in wildlife and humans. Environ. Health Perspect. 101: 378-384.

8. Davis, D. L., Bradlow, H. L., Wolff, M., Woodruff, T., Hoel, D. G. and Anton-Culver, H. 1993. Medical hypothesis: Xenoestrogens as preventable causes of breast cancer. Environ. Health Perspect. 101: 372-377.

9. Eddy, E. M., Washburn, T. F., Bunch, D. O., Goulding, E. H., Gladen, B. C., Lubahn, D. B. and Korach, K. S. 1996. Targeted disruption of the estrogen receptor gene in male mice causes alteration of spermatogenesis and infertility. Endocrinology 137: 4796-4805.

10. Gaytan, F., Pinilla, L., Aguilar, R., Lucena, M. C. and Paniagua, R. 1986. Effects of neonatal estrogen administration on rat testis development with particular reference to Sertoli cells. J. Androl. 7: 112-121.

11. Goyal, H. O., Braden, T. D., Mansour, M., Williams, C. S., Kamaleldin, A. and Srivastava, K. K. 2001. Diethylstilbestroltreated adult rats with altered epididymal sperm numbers and sperm motility parameters, but without alterations in sperm production and sperm morphology. Biol. Reprod. 64: 927-934.

12. Hess, R. A., Bunick, D., Lee, K-H., Bahr, J., Taylor, J. A., Korach, K. S. and Lubahn, D. B. 1997. A role for oestrogens in the male reproductive system. Nature (Lond.) 390: 509-512.

13. Iguchi, T., Watanabe, H., Katsu, Y., Mizutani, T., Miyagawa, S., Suzuki, A., Kohno, S., Sone, K. and Kato, H. 2002. Developmental toxicity of estrogenic chemicals on rodents and other species. Congenit. Anom. (Kyoto) 42: 94-105.

14. Kaldas, R. S. and Hughes, C. L. Jr. 1989. Reproductive and general metabolic effects of phytoestrogens in mammals. Reprod. Toxicol. 3: 81-89.

15. Lin, D., Sugawara, T., Strauss, J. F. 3rd., Clark, B. J., Stocco, D. M., Saenger, P., Rogol, A. and Miller, W. L. 1995. Role of steroidogenic acute regulatory protein in adrenal and gonadal steroidogenesis. Science 267: 1828-1831.

16. McLachlan, J. A., Newbold, R. R., Burow, M. E. and Li, S. F. 2001. From malformations to molecular mechanisms in the male: Three decades of research on endocrine disrupters. APMIS. 109: 263-272.

17. McLachlan, J. A., Newblod, R. R., Li, S. F. and Negishi, M. 1998. Are estrogens carcinogenic during development of testis? APMIS. 106: $240-244$.

18. Mori, T., Mills, K. T. and Bern, H. A. 1992. Sensitivity of the vagina and uterus of mice neonatally exposed to estrogen or androgen to postnatal treatment with estrogen or androgen. Proc. Soc. Exp. Biol. Med. 199: 466-469.

19. Müller, J. and Skakkebæk, N. E. 1984. Testicular carcinoma in situ in children with the androgen insensitivity (testicular femi- nisation) syndrome. Br. Med. J. (Clin Res Ed) 288: 1419-1420.

20. Newblod, R. R., Hanson, R. B., Jefferson, W. N., Bullock, B. C., Haseman, J. and McLachlan, J. A. 1998. Increased tumors but uncompromised fertility in the female descendants of mice exposed developmentally to diethylstilbestrol. Carcinogenesis 19: $1655-1663$.

21. Ohta, Y., Uesugi, Y. and Iguchi, T. 1995. Steroid synthesis in testicular and ovarian homogenates from adult mice treated neonatally with diethylstilbestrol. Med. Sci. Res. 23: 763-764.

22. Pelletier, G., Labrie, C. and Labrie, F. 2000. Localization of estrogen receptor $\alpha$, estrogen receptor $\beta$ and androgen receptors in the rat reproductive organ. J. Endocrinol. 165: 359-370.

23. Ramirez, R., Martin, R., Martin, J. J., Ramirez, J. R., Paniagua, R. and Santamaria, L. 1999. Changes in the number, proliferation rate and bcl-2 protein immunoexpression of epithelial and periductal cells from rat epididymis during postnatal development. J. Androl. 20: 702-712.

24. Sharpe, R. M. and Skakkebæk, N. E. 1993. Are oestrogens involved in falling sperm counts and disorders of the male reproductive tract? Lancet 341: 1392-1395.

25. Sharpe, R. M., Atanassova, N., McKinnell, C., Parte, P., Turner, K. J., Fisher, J. S., Kerr, J. B., Groome, N. P., Macpherson, S., Millar, M. R. and Saunders, P. T. 1998. Abnormalities in functional development of the Sertoli cells in rats treated neonatally with diethylstilbestrol: A possible role for estrogens in Sertoli cell development. Biol. Reprod. 59: 1084-1094.

26. Sharpe, R. M., Fisher, J. S., Millar, M. M., Jobling, S. and Sumpter, J. P. 1995. Gestational and lactational exposure of rats to xenoestrogens results in reduced testicular size and sperm production. Environ. Health Perspect. 103: 1136-1143.

27. Sharpe, R. M., Maddocks, S., Millar, M., Kerr, J. B., Saunders, P. T. and McKinnell, C. 1992. Testosterone and spermatogenesis. Identification of stagespecific, androgen-regulated proteins secreted by adult rat seminiferous tubules. J. Androl. 13: 172184.

28. Shibayama, T., Fukata, H., Sakurai, K., Adachi, T., Komiyama, M., Iguchi, T. and Mori, C. 2001. Neonatal exposure to genistein reduces expression of estrogen receptor alpha and androgen receptor in testes of adult mice. Endocr. J. 48: 655-663.

29. Sugawara, T., Holt, J. A., Driscoll, D., Strauss, J. F. 3rd., Lin, D., Miller, W. L., Patterson, D., Clancy, K. P., Hart, I. M., Clark, B. J. and Stocco, D. M. 1995. Human steroidogenic acute regulatory protein: Functional activity in COS-1 cells, tissue-specific expression, and mapping of the structural gene to $8 \mathrm{p} 11.2$ and a pseudogene to chromosome 13. Proc. Natl. Acad. Sci. U.S.A. 92: 4778-4782.

30. Sugawara, T., Lin, D., Holt, J. A., Martin, K. O., Javitt, N. B., Miller, W. L. and Strauss, J. F. 3rd. 1995. Structure of the human steroidogenic acute regulatory protein (StAR) gene: StAR stimulates mitochondrial cholesterol 27-hydroxylase activity. Biochemistry 34: 12506-12512.

31. Sugino, T., Hasegawa, Y., Kikkawa, Y., Yamaura, J., Yamagishi, M., Kurose, Y., Kogima, M., Kangawa, K. and Terashima, Y. 2002. A transient ghrelin surge occurs just before feeding in a scheduled meal-fed sheep. Biochem. Biophys. Res. Commun. 295: 255-260.

32. Sun, E. L. and Flickinger, C. J. 1979. Development of cell types and regional differences in the postnatal rat epididymis. Am. J. Anat. 154: 27-55.

33. Sun, E. L. and Flickinger, C. J. 1982. Proliferative activity in the rat epididymis during postnatal development. Anat. Rec. 
203: 273-284.

34. Toppari, J., Larsen, J. C., Christiansen, P., Giwercman, A., Grandjean, P., Guillette, L. J. Jr., Jégou, B., Jensen, T. K., Jouannet, P., Keiding, N., Leffers, H., McLachlan, J. A., Meyer, O., Müller, J., Rajpert-De Meyts, E., Scheike, T., Sharpe, R. M., Sumpter, J. S. and Skakkebæk, N. E. 1996. Male reproductive health and environmental xenooestrogens. Environ. Health Perspect. 104: 741-803.

35. Toyama, Y., Ohkawa, M., Oku, R., Maekawa, M. and Yuasa, S. 2001. Neonatally administered diethylstilbestrol retards the development of the blood-testis barrier in the rat. J. Androl. 22: 413-423.

36. Tsuchiya, M., Inoue, K., Matsuda, H., Nakamura, K., Mizutani, T., Miyamoto, K. and Minegishi, T. 2003. Expression of steroidogenic acute regulatory protein (StAR) and LH receptor in MA-10 cells. Life Sci. 73: 2855-2863.
37. van Pelt, A. M., de Rooij, D. G., van der Burg, B., van der Saag, P. T., Gustafsson, J. A. and Kuiper, G. G. 1999. Ontogeny of estrogen receptor- $\beta$ expression in rat testis. Endocrinology 140: 478-483.

38. Walters, L. M., Rourke, A. W. and Eroschenko, V. P. 1993. Purified methoxychlor stimulates the reproductive tract in immature female mice. Reprod. Toxicol. 7: 599-606.

39. Williams, K., McKinnell, C., Saunders, P. T., Walker, M., Fisher, J. S., Turner, K. J., Atanassova, N. and Sharpe, R. M. 2001. Neonatal exposure to potent and environmental oestrogens and abnormalities of the male reproductive system in the rat: evidence for importance of the androgen-oestrogen balance and assessment of the relevance to man. Hum. Reprod. Update 7: 236-247.

40. Zirkin, B. R. 1998. Spermatogenesis: its regulation by testosterone and FSH. Semin. Cell Dev. Biol. 9: 417-421. 